Jurnal Penelitian Hutan Tanaman Vol 18 No. 2, Desember 2021, 147 - 158

ISSN: 1829-6327, E-ISSN: 2442

Terakreditasi No: 21/E/KPT/2018

\title{
Uji Adaptasi Hybrid Ulat Sutra asal Tiongkok (Adaptation Test of Hybrid Silkworm from China)
}

\section{Minarningsih, Rosita Dewi dan/and Lincah Andadari}

Pusat Penelitian dan Pengembangan Hutan

Jln. Gunung Batu No. 5 P.O Box 165 Bogor, 16001, Indonesia

Telp: (0251) 8633234; 7520067; fax (0251) 8638111

*E-mail : minarningsih1975@gmail.com; rositadee@gmail.com; a.lincah@yahoo.co.id

Tanggal diterima: 19 Oktober 2021; Tanggal disetujui: 2 Desember 2021; Tanggal direvisi: 15 Desember 2021

\begin{abstract}
One of the factors that determine the success of the natural silk development in Indonesia is the supply of superior silkworm eggs. It can be done through the procurement of superior eggs both from domestic and imported. Superior silkworm eggs must have high quality and productivity. This study aims to examine the productivity and quality of hybrid silkworm eggs of the Liangguang II originating from China with the commercial local hybrid C301 and other commercial hybrids. The study was conducted at the Natural Silk Development Station, Garut Regency, West Java. The results showed that the Liangguang II hybrid had better larva quality than the local commercial hybrid C301. The Liangguang II hybrid had a shorter larval period of 1 day 2 hours, better cocoon quality, higher cocoon quality, and the same filament quality as the C301 hybrid. The Liangguang II hybrid had a higher percentage of cocoon shells (22.19\%) compared to imported F9X7 hybrids from China (20.96\%) and Bulgarian hybrids (19.26\%). The Liangguang II hybrid is recommended to be developed in the highlands in West Java.
\end{abstract}

Keywords: Productivity, commercial, imported hybrid, silkworm eggs

\begin{abstract}
Abstrak
Salah satu faktor yang menentukan keberhasilan pengembangan persutraan alam di Indonesia adalah pemenuhan bibit ulat sutra unggul. Untuk memenuhi kebutuhan tersebut, maka dapat dilakukan pengadaan bibit unggul yang berasal baik dari dalam negeri maupun impor. Bibit unggul harus memiliki kualitas dan produktivitas yang tinggi. Penelitian bertujuan untuk menguji produktivitas dan kualitas bibit ulat sutra hybrid Liangguang II asal Tiongkok dibandingkan dengan hybrid lokal komersial C301 dan hybrid lainnya. Penelitian dilakukan di Stasiun Pembinaan Persutraan Alam, Kabupaten Garut, Jawa Barat. Hasil penelitian menunjukkan bahwa bibit hybrid Liangguang II memiliki kualitas ulat yang lebih baik dari hybrid lokal komersial C301. Hybrid Liangguang II memiliki masa larva yang lebih pendek 1 hari 2 jam, kualitas kokon lebih baik, produktivitas kokon lebih tinggi, dan kualitas filamen sama dengan hybrid C301. Hybrid Liangguang II memiliki persentase kulit kokon $(22,19 \%)$ lebih unggul dibandingkan dengan hybrid impor jenis F9X7 asal Tiongkok $(20,96 \%)$ dan hybrid Bulgaria (19,26\%). Hybrid Liangguang II direkomendasikan untuk dikembangkan di dataran tinggi di Jawa Barat.
\end{abstract}

Kata kunci: Produkitivitas, komersial, hybrid impor, telur ulat sutra

https://doi.org/10.20886/jpht.2021.18.2.147-158

C.JPHT - 2018 is Open access under CC BY-NC-SA license

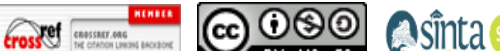




\section{Pendahuluan}

Sutra alam termasuk komoditas hasil hutan bukan kayu yang berasal dari budi daya ulat sutra jenis Bombyx mori L. Pengembangan komoditas sutra alam merupakan salah satu kegiatan perhutanan sosial untuk mendukung pemberdayaan masyarakat di sekitar hutan (Harbi, Nurrochmat, \& Kusharto, 2016). Kegiatan persutraan alam merupakan jenis usaha yang dilakukan di pedesaan dan bersifat ramah lingkungan (Chauchan \& Tayal, 2017). Kegiatan persutraan alam bersifat padat karya dan dapat dilakukan oleh lakilaki dan perempuan. Kegiatan ini mampu menghasilkan komoditi yang bernilai tinggi dan membantu menambah penghasilan masyarakat (Andadari \& Sunarti, 2015; Andadari, Ekawati \& Kuntadi, 2016; Chauchan \& Tayal, 2017).

Persutraan adalah kegiatan agroindustri dengan hasil kokon atau benang sutra, yang terdiri dari kegiatan budi daya tanaman murbei, pengadaan telur ulat sutra, budi daya ulat sutra, pengolahan kokon dan penenunan (Peraturan Menteri LHK Nomor P.37 tahun 2017). Secara teknis alur kegiatan persutraan alam terbagi menjadi dua kegiatan yaitu di tingkat hulu dan tingkat hilir. Tingkat hulu merupakan kegiatan mulai dari budi daya murbei sebagai pakan ulat sutra dan budi daya ulat sutra mulai dari telur hingga menjadi kokon (kepompong). Di tingkat hilir berupa kegiatan produksi yang mencakup mulai usaha pemintalan benang sutra dan penenunan kain sutra hingga pemasaran produknya (Hartati, 2015). Produk yang dihasilkan pada kegiatan di sektor hulu adalah kokon atau kepompong ulat sutra, sedangkan di sektor hilir menghasilkan produk benang dan kain sutra.

Keberhasilan kegiatan persutraan alam di tingkat hulu dipengaruhi oleh beberapa faktor, yaitu: bibit ulat sutra unggul, teknologi pemeliharaan, kualitas pakan (daun murbei), lingkungan pemeliharaan dan proses pengokonan. Semua faktor harus dalam kondisi terbaik dan dikerjakan secara optimal untuk dapat menghasilkan produk kokon dan benang sutra yang berkualitas tinggi ( Andadari et al., 2016; Chauchan \& Tayal, 2017).

Kebutuhan akan bahan baku sutra di tingkat hilir semakin meningkat. Namun pasokan bahan baku sutra dari dalam negeri belum mampu memenuhi kebutuhan sektor hilir. Data impor sutra ke Indonesia meningkat hampir setiap tahun. Asosiasi Pertekstilan Indonesia mengemukakan bahwa volume impor benang sutra pada tahun 2018 sebanyak 208 ton. Nilai impor ini meningkat sebanyak $60 \%$ dari tahun sebelumnya (Arief, 2019).

Salah satu faktor yang menentukan keberhasilan dalam pemeliharaan ulat sutra adalah penggunaan bibit ulat sutra yang berkualitas unggul (Chauchan \& Tayal, 2017). Saat ini di Indonesia bibit ulat sutra komersial yang dipelihara oleh petani adalah jenis C301 yang berasal dari Perum Perhutani. Bibit ulat sutra C301 merupakan jenis hybrid dengan keunggulan memiliki persentase penetasan yang tinggi di atas 90\% (Andadari et al., 2016). Namun pemeliharaan ulat dengan kondisi lingkungan yang sangat beragam seperti di Indonesia memerlukan jenis hybrid ulat yang sesuai. Selain itu, penggunaan jenis ulat yang sama pada kondisi lingkungan yang berbeda-beda dapat berpengaruh pada produktivitas dan kualitas kokon yang dihasilkan sehingga produksinya cenderung fluktuatif (Andadari \& Kuntadi, 2014). Karena itu, diperlukan bibit-bibit unggul baru sebagai salah satu upaya untuk memperkaya pilihan jenis bibit sehingga diharapkan akan meningkatkan kegiatan dan produktivitas usaha persutraan alam untuk dapat memenuhi pasokan bahan baku sutra.

Bibit ulat sutra jenis Liangguang II asal Tiongkok diusulkan menjadi kandidat hybrid unggul pendamping C301. Bibit jenis Liangguang II merupakan hybrid komersial yang banyak dibudidayakan di bagian selatan Tiongkok (Chen et al., 2014). Hybrid Liangguang II memiliki parameter 
kualitas kokon yang baik, yaitu memiliki berat kulit kokon 0,32 gram dan persentase kulit kokon 20,32\% (Qin et al., 2020). Bibit lokal C301 juga memiliki kualitas kokon yang baik dengan berat kulit kokon 0,30 gram dan persentase kulit kokon 20,96\% (Andadari \& Kuntadi, 2014).

Sesuai ketentuan Peraturan Menteri Lingkungan Hidup dan Kehutanan Nomor P.37/MENLHK/2017 tentang Pengadaan dan Peredaran Telur Ulat Sutra, setiap pemasukan bibit harus melalui serangkaian uji adaptasi untuk menentukan kelayakannya dikembangkan di Indonesia. Berdasarkan hal tersebut, penelitian ini dilakukan dengan tujuan untuk mengetahui kualitas ulat sutra, kualitas kokon dan kualitas filamen pada bibit ulat sutra jenis Liangguang II. Sebagai pembanding digunakan hybrid komersial lokal jenis C301 yang dibudidayakan secara bersamaan di lokasi yang sama.

\section{Metodologi}

\subsection{Waktu dan Lokasi Penelitian}

Penelitian dilaksanakan pada bulan Agustus sampai September 2018. Uji adaptasi bibit ulat sutra hybrid asal Tiongkok dilakukan di Stasiun Pembinaan Persutraan Alam (SPPA), Desa Sirnagalih, Kecamatan Cisurupan Kabupaten Garut, Provinsi Jawa Barat. Lokasi penelitian berada di ketinggian $1.050 \mathrm{~m}$ di atas permukaan laut (mdpl) dengan suhu udara rata-rata harian $17-23^{\circ} \mathrm{C}$ dan kelembapan rata-rata $75-84 \%$.

\subsection{Metode}

\subsubsection{Persiapan}

Penyiapan kebun murbei (Morus sp.) sebagai pakan ulat sutra. Tanaman murbei yang dimanfaatkan untuk ulat kecil adalah tanaman murbei usia pangkas 25 - 30 hari. Tanaman murbei untuk pakan ulat besar adalah tanaman murbei usia pangkas 70 - 80 hari. Pada tahapan persiapan juga dilakukan pembersihan atau desinfeksi ruangan dan alat-alat yang digunakan untuk pemeliharaan ulat sutra.

\subsubsection{Pemeliharaan ulat sutera}

Pemeliharaan ulat sutra dilakukan sesuai dengan standar operasional dan prosedur dalam pemeliharaan ulat sutra (Andadari et al., 2014). Pemeliharaan ulat kecil dilakukan dari masa pemberian makan (hakitate) pada usia instar I sampai dengan instar III. Pemeliharaan ulat besar dilakukan pada usia instar IV sampai dengan instar V. Setelah akhir instar V ulat sutra siap mengokon, dipindahkan ke alat pengokonan (seriframe) dengan masing-masing seriframe berisi 200 ekor ulat sutra.

\subsubsection{Rancangan penelitian}

Ada dua jenis bibit ulat sutra yang diujikan di penelitian ini yaitu: (a) bibit ulat sutra hybrid jenis Liangguang II (932 Furong x 7532 Xianghui) produksi Tiongkok; (b) bibit ulat sutra hybrid komersial jenis C301 produksi Perum Perhutani (Kesatuan Pengusaha Sutra Alam) Soppeng. Parameter yang diamati yaitu: (a) kualitas ulat sutra (dinilai berdasarkan persentase penetasan dan lama pemeliharaan larva ulat sutra sampai dengan mengokon); (b) kualitas kokon (dinilai berdasarkan bobot kokon, persentase kokon cacat, persentase kulit kokon, serta jumlah kokon per 0,5 liter dan 0,25 liter); c) kualitas filamen (dinilai berdasarkan panjang filamen, persentase filamen, ketebalan serat (denier) dan daya gulung). Jumlah sampel untuk masingmasing parameter seperti pada Tabel 1.

Penelitian ini juga membandingkan parameter-parameter hasil uji adaptasi hybrid jenis Liangguang II dengan data sekunder hasil uji adaptasi yang telah dilakukan sebelumnya untuk hybrid jenis F9X7 asal Tiongkok (Andadari \& Kuntadi, 2014) dan hybrid dari Bulgaria (Andadari et al., 2016). Uji adaptasi hybrid jenis F9X7 dilaksanakan pada tahun 2009 berlokasi di Soppeng dengan ketinggian tempat 100 mdpl dan Enrekang dengan ketinggian 
tempat 800 mdpl. Adapun uji adaptasi jenis Bulgaria dilaksanakan pada tahun 2012, berlokasi di Cianjur dengan ketinggian tempat $700 \mathrm{mdpl}$.

Data hasil penelitian kemudian dianalisis secara statistik menggunakan software Minitab. Analisis yang dilakukan adalah uji beda rata-rata menggunakan Uji T-Student.

\section{Hasil dan Pembahasan}

\subsection{Hasil}

\subsubsection{Kualitas ulat sutera}

Kualitas ulat sutra dapat dilihat dari dua parameter, yaitu persentase penetasan dan umur larva. Ciri dari telur ulat sutra yang menetas berwarna abu dan telur yang tidak menetas berwarna kuning. Hasil pengamatan terhadap kualitas ulat sutra hybrid jenis Liangguang II dan C301 disajikan pada Tabel 2.

Persentase penetasan telur hybrid Liangguang II lebih tinggi daripada bibit ulat sutra komersial lokal (hybrid C301) (p $<0,01)$. Meskipun demikian, persentase penetasan telur kedua hybrid ulat sutera masih kurang optimal karena kurang dari $90 \%$.
Umur larva hybrid Liangguang II lebih pendek dari hybrid komersial C301. Perbedaan lama umur larva kedua hybrid mencapai 1 hari 2 jam. Berdasarkan parameter persentase penetasan dan umur larva, ulat sutra hybrid Liangguang II memiliki kualitas ulat yang lebih baik bila dibandingkan dengan ulat sutra hybrid komersial C301.

\subsubsection{Kualitas kokon}

Kokon merupakan produk utama dari pemeliharaan ulat sutra di sektor hulu. Kualitas kokon dinilai berdasarkan parameter bobot kokon, persentase kokon cacat, dan persentase kulit kokon. Data pengamatan kualitas kokon ulat sutra hybrid Liangguang II dan C301 disajikan pada Tabel 3.

Bobot kokon per butir hybrid Liangguang II lebih berat daripada hybrid komersial C301 ( $\mathrm{p}<0,01)$. Jumlah kokon per 0,5 liter dan per 0,25 gram untuk hybrid Liangguang II lebih sedikit daripada hybrid komersial C301 ( $\mathrm{p}<0,01)$. Dikarenakan bobot kokon per butir hybrid Liangguang II lebih berat dibandingkan hybrid komersial C301, maka jumlah kokon per satuan $(0,5$ liter dan 0,25 gram) lebih sedikit bila dibandingkan hybrid komersial C301.

Tabel (Table) 1. Jumlah sampel pada uji adaptasi hybrid Liangguang II dan C301 (The number of samples on the adaptation test of Liangguang II and C301 hybrids)

\begin{tabular}{lcc}
\hline \multirow{2}{*}{$\begin{array}{c}\text { Parameter yang diuji (Tested parameters) } \\
\text { Cumlah sampel per jenis }\end{array}$} & $\begin{array}{c}\text { Jumber } \\
\text { (Number of samples per } \\
\text { type) }\end{array}$ \\
\cline { 2 - 3 } & C301 & Lingguang II \\
\hline 1. Persentase penetasan (Egg hatching percentage) & 6 & 6 \\
2. Bobot kokon (Cocoon weight) & 18 & 21 \\
3. Persentase kokon cacat (Percentage of deformed cocoon) & 31 & 31 \\
4. Persentase kulit kokon (Percentage of cocoon shell) & 10 & 18 \\
5. Panjang filament (Filament length) & 32 & 32 \\
6. Persentase filament (percentage of filement) & 32 & 32 \\
7. Ketebalan filament (Filament thickness) & 32 & 32 \\
8. Persentase daya gulung (Percentage of spinning) & 32 & 32 \\
\hline
\end{tabular}


Persentase kokon cacat hybrid Liangguang II berbeda nyata bila dibandingkan dengan hybrid komersial C301. Liangguang II menghasilkan persentase kokon cacat yang lebih sedikit dibandingkan komersial C301 ( $\mathrm{p}<0,01$ ). Persentase kulit kokon hybrid Liangguang lebih tinggi bila dibandingkan dengan hybrid $\mathrm{C} 301(\mathrm{p}<0,01)$.

\subsubsection{Kualitas filamen}

Kualitas filamen serat sutra dinilai berdasakan panjang filamen, persentase filamen, ketebalan filamen dan daya gulung filamen. Data pengamatan uji filamen sutra jenis hybrid Liangguang II dan hybrid C301 disajikan pada Tabel 4.

Berdasarkan hasil analisis data, nilai rata-rata panjang filamen, persentase filamen, ketebalan filamen dan persentase daya gulung filamen kedua jenis hybrid tidak berbeda nyata. Dengan demikian, kualitas filamen pada hybrid Liangguang II dan C301 adalah sama.

\subsubsection{Perbandingan kualitas bibit hybrid Liangguang II dengan hybrid impor (F9X7 dan Bulgaria)}

Penelitian ini juga telah dilakukan uji perbandingan parameter-parameter kualitas bibit hybrid ulat sutra Liangguang II dengan beberapa hybrid impor lainnya yang telah dilakukan kegiatan uji adaptasi di tiga lokasi, yaitu: jenis F9X7 yang berlokasi di Soppeng, jenis F9X7 yang berlokasi di Enrekang, dan jenis Bulgaria yang berlokasi di Cianjur.

Apabila dibandingkan antara hybrid Liangguang II dan hybrid F9X7S (lokasi Soppeng) pada Tabel 6, hybrid F9X7S lebih unggul pada lima parameter (persentase penetasan, berat kulit kokon, panjang filamen, rendemen filamen dan daya gulung). Hybrid Liangguang II unggul pada tiga parameter (bobot kokon, persen kulit kokon dan tebal denier). Hasil uji perbandingan parameter hybrid Liangguang II dan hybrid F9X7S berbeda nyata untuk semua parameter kecuali persentase penetasan dan daya gulung. Data hasil pengujian beberapa parameter ulat sutra hybrid Liangguang II, F9X7 (Soppeng), F9X7 (Enrekang) dan Bulgaria disajikan pada Tabel 5.

\subsection{Pembahasan}

Kualitas ulat sutra berkaitan dengan kualitas bibit telur ulat sutra karena memiliki parameter yang sama, yaitu persentase penetasan. Persentase penetasan yang tinggi merupakan hal yang sangat utama dan menjadi tolok ukur di dalam penentuan kualitas bibit telur ulat sutra (Andadari, 2016). Apabila dilihat dari persentase penetasannya, baik hybrid Liangguang II maupun hybrid komersial C301 memiliki persentase penetasan yang kurang optimal. Daya tetas telur kedua jenis hybrid masih jauh di bawah standar daya tetas telur untuk bibit komersial, yakni di atas 90\% (Andadari \& Kuntadi, 2014).

Temperatur dan kelembapan merupakan salah satu faktor yang dapat memengaruhi daya tetas telur ulat sutra. Temperatur rata-rata harian di lokasi pemeliharaan antara $17-23^{\circ} \mathrm{C}$ dengan ratarata kelembapan $75-84 \%$, sedangkan di tempat asalnya di Tiongkok, pemeliharaan ulat sutra Liangguang II menggunakan temperatur $25^{\circ} \mathrm{C}$ dan kelembaban antara $80-85 \%$. (Chen et al., 2014).

Umur larva dimulai dari saat telur menetas (hakitate) sampai dengan ulat siap mengokon. Ulat sutra yang dipelihara pada lokasi dengan ketinggian tempat yang tinggi akan memiliki umur larva yang lebih panjang jika dibandingkan dengan pemeliharaan di tempat yang lebih rendah. Lamanya umur larva dipengaruhi oleh lingkungan yaitu iklim dan temperatur setempat (Andadari et al, 2016). 
Tabel (Table) 2. Persentase penetasan telur dan umur larva (The hatchability percentage of egg and larval age)

\begin{tabular}{lcl}
\hline $\begin{array}{l}\text { Jenis } \\
\text { (Type) }\end{array}$ & $\begin{array}{c}\text { Persentase penetasan (\%) } \\
\text { (Hatching percentage) }\end{array}$ & \multicolumn{1}{c}{$\begin{array}{c}\text { Umur larva (Hari) } \\
\text { (Larval age) (Days) }\end{array}$} \\
\hline 1. C301 & $56,27 \pm 2,94 \mathrm{~b}$ & $\begin{array}{l}\text { 34 hari 3 jam (34 days and 3 } \\
\text { hours) } \\
\text { 2. Liangguang II }\end{array}$ \\
& $70,22 \pm 3,59 \mathrm{a}$ & $\begin{array}{l}\text { 33 hari 1 jam (33 days and 1 } \\
\text { hour) }\end{array}$ \\
& &
\end{tabular}

Sumber (Source): Data primer (Primer data)

Keterangan (Remarks): Huruf yang sama di belakang nilai rata-rata pada baris yang sama menunjukkan tidak berbeda nyata (The same letter behind the mean value at the same row denotes no significant difference)

Tabel (Table ) 3. Kualitas kokon (The quality of the cocoon)

\begin{tabular}{lcc}
\hline \multicolumn{1}{c}{ Parameter } & \multicolumn{2}{c}{ Jenis (Type) } \\
& C301 & Liangguang II \\
\hline 1. Bobot kokon (Cocoon weight) (gram) & $1,36 \pm 0,06 \mathrm{~b}$ & $1,52 \pm 0,04 \mathrm{a}$ \\
2. Persentase kokon cacat (Percentage of deformed & $0,34 \pm 0,01 \mathrm{a}$ & $0,29 \pm 0,01 \mathrm{~b}$ \\
cocoon) $(\%)$ & & \\
3. Persentase kulit kokon (Percentage of cocoon shell) & $21,66 \pm 0,70 \mathrm{~b}$ & $22,19 \pm 0,2) \mathrm{a}$ \\
$\quad(\%)$ & & \\
4. Jumlah kokon per 0,5 liter (Number of cocoon per & $53,00 \mathrm{a}$ & $45,00 \mathrm{~b}$ \\
$\quad$ O,5 liter) & & \\
5. Jumlah kokon per 250 gram (Number of cocoon per & $194,00 \mathrm{a}$ & $167,00 \mathrm{~b}$ \\
\hline 250 gram)
\end{tabular}

Sumber (Source): Data primer (Primer data)

Keterangan (Remarks): Huruf yang sama di belakang nilai rata-rata pada baris yang sama menunjukkan tidak berbeda nyata (The same letter behind the mean value at the same row denotes no significant difference)

Tabel (Table) 4. Uji Filamen (Test of filament)

\begin{tabular}{lcc}
\hline \multirow{2}{*}{ Parameter } & \multicolumn{2}{c}{ Jenis (Types) } \\
\cline { 2 - 3 } & C301 & Liangguang II \\
\hline 1. Panjang filamen (Filament length) $(\mathrm{m})$ & $876,7 \pm 98,1$ a & $871,0 \pm 154 \mathrm{a}$ \\
2. Persentase filamen (Percentage of filament) $(\%)$ & $16,80 \pm 2,75 \mathrm{a}$ & $16,27 \pm 2,19 \mathrm{a}$ \\
3. Ketebalan filamen (Filament thickness) (Denier) & $93,8 \pm 16,8 \mathrm{a}$ & $92,7 \pm 17,4 \mathrm{a}$ \\
2.Persentase daya gulung (Percentage of spinning) $(\%)$ & $2,44 \pm 0,27 \mathrm{a}$ & $2,51 \pm 0,33 \mathrm{a}$ \\
\hline
\end{tabular}

Sumber (Source): Data primer (Primer data)

Keterangan (Remarks): Huruf yang sama di belakang nilai rata-rata pada baris yang sama menunjukkan tidak berbeda nyata (The same letter behind the mean value at the same row denotes no significant difference) 
Tabel (Table) 5. Hasil uji adaptasi ulat sutra hybrid Liangguang II di Garut, F9X7 di Soppeng dan Enrekang, dan hybrid asal Bulgaria di Cianjur (The results of adaptation tests of the silkworm Liangguang II hybrid in Garut, F9X7 in Soppeng and Enrekang, and hybrid from Bulgaria in Cianjur)

\begin{tabular}{|c|c|c|c|c|c|c|c|}
\hline \multirow[b]{2}{*}{ No. } & \multirow{2}{*}{$\begin{array}{c}\text { Parameter } \\
\text { (Parameters) }\end{array}$} & \multicolumn{6}{|c|}{ Hybrid ulat sutra (Silkworm Hybrids) } \\
\hline & & Liangguang II $^{1}$ & $\mathrm{~F} 9 \mathrm{X}^{2} \mathrm{~S}^{2}$ & Liangguang II $^{1}$ & $\mathrm{~F} 9 \mathrm{X} 7 \mathrm{E}^{3}$ & Liangguang II $^{1}$ & Bulgaria $^{4}$ \\
\hline 1. & $\begin{array}{l}\text { Persen tetas } \\
(\text { Egg hatchability })(\%)\end{array}$ & $(70,22 \pm 3,59) \mathrm{a}$ & $(91,10 \pm 1,78) \mathrm{a}$ & $(70,22 \pm 3,59) b$ & $(90,27 \pm 1,62) a$ & $(70,22 \pm 3,59) b$ & $97,38 \mathrm{a}$ \\
\hline 2. & $\begin{array}{l}\text { Bobot kokon (Cocoon weight) } \\
\text { (gram) }\end{array}$ & $(1,52 \pm 0,04) \mathrm{a}$ & $(1,44 \pm 0,09) b$ & $(1,52 \pm 0,04) b$ & $(1,57 \pm 0,03) \mathrm{a}$ & $(1,52 \pm 0,04) a$ & $1,63 \mathrm{~b}$ \\
\hline 3. & $\begin{array}{l}\text { Berat kulit kokon (Cocoon shell } \\
\text { weight) } \\
\text { (gram) }\end{array}$ & $(0,29 \pm 0,01) b$ & $(0,30 \pm 0,01) \mathrm{a}$ & $(0,29 \pm 0,01) b$ & $(0,32 \pm 0,01) a$ & $(0,29 \pm 0,01) b$ & \\
\hline 4. & $\begin{array}{l}\text { Persen kulit kokon (Cocoon shell } \\
\text { ratio) }(\%)\end{array}$ & $(22,19 \pm 0,28) a$ & $(20,96 \pm 0,31) b$ & $(22,19 \pm 0,28) a$ & $(20,58 \pm 0,23) b$ & $(22,19 \pm 0,28) a$ & $19,26 \mathrm{~b}$ \\
\hline 5. & $\begin{array}{l}\text { Panjang filament (Filament length) } \\
(\mathrm{m})\end{array}$ & $(871,0 \pm 154) b$ & $(994,84 \pm 45,27) \mathrm{a}$ & $(871,0 \pm 154) b$ & $(889,08 \pm 39,24) \mathrm{a}$ & $(871,0 \pm 154) \mathrm{a}$ & \\
\hline 6. & $\begin{array}{l}\text { Rendemen filament (Filament } \\
\text { percentage) } \\
(\%)\end{array}$ & $(16,27 \pm 2,19) b$ & $(17,91 \pm 0,59) \mathrm{a}$ & $(16,27 \pm 2,19) b$ & $(19,14 \pm 0,39) a$ & $(16,27 \pm 2,19) b$ & \\
\hline 7. & Daya gulung (Reelability) (\%) & $(92,7 \pm 17,4) \mathrm{a}$ & $(95,56 \pm 5,34) a$ & $(92,7 \pm 17,4) \mathrm{a}$ & $(85,57 \pm 10,47) b$ & $(92,7 \pm 17,4) \mathrm{a}$ & \\
\hline 8. & $\begin{array}{l}\text { Tebal Denier (Denier thickness) } \\
\text { (Denier) }\end{array}$ & $(2,51 \pm 0,33) \mathrm{a}$ & $(2,37 \pm 0,009) b$ & $(2,51 \pm 0,33) \mathrm{a}$ & $(2,97 \pm 0,14) \mathrm{a}$ & $(2,51 \pm 0,33) b$ & \\
\hline
\end{tabular}

Keterangan (Remarks): ${ }^{1}$ Lokasi Garut-Jawa Barat pada ketinggian 1.050 mdpl (Garut, West Java at the height of 1,050 m above sea level/asl); Lokasi Soppeng pada ketinggian $100 \mathrm{mdpl}$ Soppeng, South Sulawesi at the height of $100 \mathrm{~m}$ asl); ${ }^{3}$ Lokasi Enrekang pada ketinggian $800 \mathrm{Mdpl}$ (Enrekang, South Sulawesi at the height of $800 \mathrm{~m}$ asl); ${ }^{4}$ Lokasi Cianjur pada ketinggian $700 \mathrm{mdpl}$ (Cianjur, West Java, at the height of $700 \mathrm{~m}$ asl); L = hybrid Liangguang II (hybrid of Liangguang II); F9X7S = hybrid F9X7 dengan lokasi uji adaptasi di Soppeng (hybrid of F9X7 with location of adaptation test in Soppeng ); F9X7E = hybrid F9X7 dengan lokasi uji adaptasi di Enrekang (hybrid of F9X7 with location of adaptation test in Enrekang); Bulgaria = hybrid Bulgaria (hybrid of Bulgaria). Huruf yang sama di belakang nilai rata-rata pada baris yang sama menunjukkan tidak berbeda nyata (The same letter behind the mean value on the same row denotes no significant difference). 
Hasil penelitian memperlihatkan bahwa ulat sutra hybrid jenis C301 memiliki umur larva 34 hari 3 jam dan Liangguang II memiliki umur larva 33 hari 1 jam. Umur larva hybrid lokal lebih lama 1 hari 2 jam bila dibandingkan dengan ulat sutra hybrid jenis Liangguang II. Dengan kata lain, dilihat dari parameter umur larva, bibit Liangguang II memiliki kualitas yang lebih baik daripada bibit lokal. Meskipun demikian, pada uji adaptasi ini rata-rata umur larva hybrid Liangguang II masih jauh lebih lama bila dibandingkan dengan hasil penelitian Qin et al. (2020) di Tiongkok dengan hybrid yang sama, yaitu berkisar 23 - 25 hari. Lokasi uji adaptasi di Garut yang lebih tinggi dari lokasi penelitian Qin et al. (2020) di Universitas Southwest, Tiongkok, sangat mungkin menjadi salah satu penyebabnya.

Kualitas ulat sutra akan memengaruhi kualitas kokon yang dihasilkan. Bobot kokon, bobot kulit kokon, dan rasio kulit kokon adalah parameter penentu yang secara ekonomi paling penting di dalam budi daya ulat sutra (Mirhosseini et al., 2010). Hasil penelitian menunjukkan bahwa kualitas ulat sutra hybrid Liangguang II memiliki kualitas kokon yang baik dan telah memenuhi standar mutu kokon.

Dari proses pemeliharaan ulat sutra, maka produk akhir berupa kokon yang berkualitas menjadi parameter penting karena memengaruhi produktivitas dan nilai ekonomi produk akhir. Hasil penelitian menunjukkan produksi kokon pada hybrid
Liangguang II lebih tinggi daripada hybrid komersial C301. Hybrid Liangguang II mampu menghasilkan kokon seberat 22,9 kg kokon per box, sedangkan hybrid komersial C301 20,8 kg kokon per box..

Kualitas produksi ulat sutra hybrid jenis Liangguang II menunjukkan hasil yang lebih baik dibandingkan dengan jenis ulat sutra hybrid komersial C301 untuk parameter bobot kokon per butir dan persentase kulit kokon. Besarnya nilai persentase kulit kokon sangat ditentukan oleh berat kokon dan berat kulit kokon (Andadari, 2016). Pada penelitian ini, ratarata persentase kulit kokon yang dihasilkan oleh kedua hybrid adalah 22,25\% (hybrid Liangguang II) dan 22,10\% (hybrid C301). Kedua hybrid menghasilkan persentase kulit kokon yang lebih tinggi daripada hasil produksi hybrid di daerah tropis. Menurut Atmosoedarjo et al. (2000) rata-rata produksi hybrid di daerah tropis sebesar $18,0-22,0 \%$.

Standar Nasional Indonesia (SNI) telah menetapkan standar kokon segar ulat sutra berdasarkan hasil uji visual, yaitu berat kokon, persentase kulit kokon dan persentase kokon cacat (Badan Standarisasi Nasional, 2010). Standar lainnya berdasarkan kelas mutu kokon ulat sutra dari Balai Persutraan Alam (BPA) (Balai Persutraan Alam, 2010). Klasifikasi kelas mutu kokon hybrid ulat sutra berdasarkan SNI dan BPA tersaji pada Tabel 6.

Tabel (Table) 6. Klasifikasi kelas mutu kokon hybrid ulat sutra di Indonesia (Quality class classification of silkworm hybrid cocoons in Indonesia)

\begin{tabular}{|c|c|c|c|c|c|c|}
\hline \multirow[t]{2}{*}{$\begin{array}{l}\text { Grade } \\
\text { (Grade) }\end{array}$} & \multicolumn{2}{|c|}{$\begin{array}{c}\text { Bobot kokon (Cocoon } \\
\text { weight) (gram) }\end{array}$} & \multicolumn{2}{|c|}{$\begin{array}{l}\text { Persentase kulit kokon } \\
\text { (percentage of cocoon } \\
\text { shell) }(\%)\end{array}$} & \multicolumn{2}{|c|}{$\begin{array}{c}\text { Persentase kokon cacat } \\
\text { (Percentage of deformed } \\
\text { cocoon) }(\%)\end{array}$} \\
\hline & SNI & BPA & SNI & $\overline{B P A}$ & SNI & BPA \\
\hline A & $\geq 2,0$ & $\geq 2,0$ & $\geq 23,0$ & $\geq 25$ & $\leq 2,0$ & $\leq 1,0$ \\
\hline B & $1,7-2,0$ & $1,5-1,9$ & $20,0-23,0$ & $20-24,9$ & $2,0-5,0$ & $1,1-4,0$ \\
\hline $\mathrm{C}$ & $1,3-1,7$ & $1,0-1,4$ & $17,0-20,0$ & $15-19,9$ & $5,0-8,0$ & $4,1-8,0$ \\
\hline D & $<1,3$ & $\leq 0,9$ & $<17,0$ & $\leq 14,9$ & $>8,0$ & $\geq 8,1$ \\
\hline
\end{tabular}

Sumber (Source): BSN (2010); BPA (2010) 
Berdasarkan klasifikasi kelas mutu kokon tersebut, maka kokon produksi kedua hybrid berada pada kisaran grade B - D. Klasifikasi mutu kokon untuk suatu jenis hybrid tidak akan selalu sama. Terbuka kemungkinan akan ada perbaikan pada kondisi pemeliharaan yang berbeda, meskipun kisarannya tidak akan terlalu jauh mengingat adanya faktor genetik dari hybrid yang dipelihara. Penggunaan jenis ulat yang sama untuk pemeliharaan pada kondisi tempat yang beragam menghasilkan produksi kokon yang bervariasi (Andadari \& Kuntadi, 2014). Selain itu, pemberian pakan dengan jenis murbei yang berkualitas tinggi dari daun murbei hybrid unggul dapat meningkatkan kualitas kokon yang dihasilkan (Sudan \& Bukhari, 2021).

Penetapan mutu kokon di pasaran belum sesuai dengan standar klasifikasi mutu kokon (SNI dan BPA). Dalam proses jual beli kokon misalnya di pasar sutra di Kabupaten Enrekang, Sulawesi Selatan, penjual dan pembeli akan melihat pada besarnya kokon, yang biasanya dilihat dari jumlah butir kokon per takaran yang digunakan (ditimbang per $\mathrm{kg}$ atau gelas literan). Oleh karena itu, dalam penelitian ini disertakan parameter jumlah butir kokon per 0,5 liter dan per 250 gram. Parameter penghitungan jumlah butir kokon per 0,5 liter dan per 250 gram merupakan parameter pendukung yang menunjukkan bahwa kokon Liangguang II memiliki butiran yang lebih besar dibanding dengan kokon jenis C301. Hal ini sesuai dengan parameter bobot kokon hybrid Liangguang II yang lebih besar dibanding kokon hybrid C301.

Benang sutra dapat dikatakan merupakan produk akhir dari kegiatan budi daya ulat sutra di bagian hulu. Nilai ekonomis dari produk kegiatan ini sangat tergantung pada kualitas benang yang dihasilkan. Kualitas kokon sutra akan memengaruhi kualitas benang sutra yang dihasilkan. Benang sutra adalah bahan baku dari kain sutra yang memiliki nilai ekonomi tinggi. Menurut Sajgotra \& Gupta (2018), karakter filamen dari kokon yang dihasilkan memiliki pengaruh yang lebih besar bukan saja bagi para pemintal tetapi juga secara keseluruhan berpengaruh terhadap keberhasilan industri sutra alam. Karakter filamen yang dimaksud adalah panjang filamen/serat, rendemen pintal (persentase pemintalan), denier atau ukuran ketebalan serat sutra dan daya gulung. Andadari \& Kuntadi (2014) menyebutkan bahwa kualitas filamen sutra sangat penting dalam pemintalan karena akan memengaruhi benang sutra yang diperoleh. Semakin panjang filamen, maka semakin besar kandungan sutranya (Andadari, 2016).

Salah satu parameter dari kualitas filamen adalah panjang filamen. Panjang filamen sutra yang baik adalah berkisar 800 - 1.500 m. Kedua hybrid (Liangguang II dan C301) menghasilkan kokon dengan panjang filamen yang baik (> $800 \mathrm{~m}$ ). Terdapat korelasi antara panjang filamen dengan persentase kulit kokon (Andadari, 2016). Hal ini sesuai dengan hasil penelitian bahwa hybrid Liangguang II menghasilkan kokon dengan panjang filamen dan persentase kulit kokon yang lebih tinggi dibandingkan dengan hybrid C301.

Parameter lain yang penting di dalam penentuan kualitas serat sutra adalah ketebalan serat dan daya gulung filamen. Besar kecilnya diameter serat sutra dinyatakan dengan ukuran yang dikenal dengan istilah denier. Nilai denier adalah nilai yang menyatakan berat serat (dalam satuan gram) dengan panjang $9.000 \mathrm{~m}$ (Noerati, Gunawan, Ichwan, \& Sumihartati, 2013).

Denier filamen akan berpengaruh pada jumlah kokon yang diperlukan untuk mendapatkan benang sutra dengan ketebalan tertentu sesuai dengan kebutuhan konsumen (penenun). Sajgotra \& Gupta (2018) menyatakan bahwa panjang filamen yang lebih pendek umumnya akan menghasilkan denier yang relatif tipis. Daya gulung adalah kemampuan serat sutra untuk terurai dan tergulung pada saat kokon 
dipintal, semakin tinggi daya gulung akan semakin efisien dalam proses pemintalan (mengurangi pekerjaan menyambung serat karena putus) dan jika benang di uji kerapihan akan semakin rapih benang yang dihasilkan karena tidak banyak terdapat simpul-simpul.

Pada penelitian ini kualitas filamen berdasarkan parameter panjang filamen, persentase filamen, ketebalan filamen dan persentase daya gulung pada kedua jenis hybrid (Liangguang II dan C301) memiliki kualitas filamen yang sama. Hal ini berbeda dengan penelitian Andadari \& Kuntadi (2014) yang menunjukkan kualitas filamen hybrid lokal jenis C301 lebih baik daripada hybrid F9X7 yang diimpor dari Tiongkok. Mutu filamen dipengaruhi juga oleh kualitas bibit, kualitas daun, lingkungan, kondisi saat mengokon, seleksi kokon, penyimpanan dan pengangkutan kokon (Andadari \& Sunarti, 2015).

Perbandingan parameter kualitas hybrid ulat sutra antara hybrid Liangguang II dan hybrid F9X7E (lokasi Enrekang) pada Tabel 6 menunjukkan bahwa hybrid F9X7E lebih unggul daripada hybrid Liangguang II pada tujuh parameter (persentase penetasan, bobot kokon, berat kulit kokon, panjang filamen, rendemen filament, dan tebal denier). Hybrid Liangguang II unggul pada dua parameter yaitu persen kulit kokon dan daya gulung. Hasil uji perbandingan parameter hybrid Liangguang II dan hybrid F9X7S berbeda nyata untuk semua parameter kecuali tebal denier.

Apabila hybrid Liangguang II dibandingkan dengan hybrid Bulgaria seperti pada pada Tabel 6 menunjukkan bahwa hybrid Bulgaria lebih unggul pada parameter persentase penetasan yaitu persentase penetasan dan bobot kokon. Hybrid Liangguang II memiliki keunggulan pada parameter persen kulit kokon.

Persentase kulit kokon hybrid impor dari Tiongkok jenis Liangguang II menunjukkan hasil yang lebih baik apabila diperbandingkan dengan dua hybrid impor yang pernah diuji adaptasi. Hal ini menjadi keunggulan bagi hybrid impor Liangguang II, khususnya di dalam peningkatan produktivitas kokon dan nilai jual kokon, karena persentase kulit kokon adalah salah satu tolok ukur untuk penentuan harga jual kokon (Andadari \& Kuntadi, 2014). Adanya peningkatan persentase kulit kokon, diharapkan harga jual kokon di tingkat petani menjadi lebih baik.

\section{Kesimpulan dan Saran}

\subsection{Kesimpulan}

Hasil uji adaptasi menunjukkan bahwa bibit ulat sutra hybrid Liangguang II memiliki kualitas ulat, kualitas kokon yang lebih baik bila dibandingkan dengan bibit ulat sutra komersial C301. Hybrid Liangguang II memiliki masa larva yang relatif lebih pendek 1 hari 2 jam, dengan bobot kokon per butir 1,52 gram, persentase kokon normal 92,22\% dan persentase kulit kokon 22,25\%. Hybrid Liangguang II menghasilkan kualitas filamen sutra yang sama dengan jenis C301. Panjang filamen hybrid Liangguang II mencapai 886,5 $\mathrm{m}$ dan ketebalan serat sutera 2,51 denier. Produktivitas kokon hybrid Liangguang II (22,9 kg/box) lebih tinggi daripada hybrid komersial C301 (20,8 kg/box). Apabila dibandingkan dengan hybrid impor lainnya, maka hybrid Liangguang II memiliki keunggulan persentase kulit kokon yang lebih tinggi daripada hybrid F9X7 asal Tiongkok dan hybrid asal Bulgaria.

\subsection{Saran}

Bibit hybrid Liangguang II memiliki kualitas yang baik dan dapat digunakan sebagai alternatif pendamping bibit hybrid komersial lokal C301 untuk daerah penyaluran bibit di dataran tinggi di Jawa Barat.

\section{Ucapan Terima Kasih}

Penulis mengucapkan terima kasih kepada Dr. Darwo yang telah membimbing 
di dalam analisis statistik dan penulisan naskah KTI. Penulis menyampaikan terima kasih kepada Pusat Penelitian dan Pengembangan Hutan, Balai Perhutanan Sosial dan Kemitraan Lingkungan Wilayah Jawa, Bali Nusa Tenggara dan PT Indo Donfeng Motor. Penulis juga mengucapkan terima kasih untuk teknisi pak Heri dan pak Topik serta staf di Stasiun Pembinaan Persutraan Alam Cisurupan-Kabupaten Garut yang membantu kegiatan pemeliharaan ulat sutra.

\section{Daftar Pustaka}

Andadari, L., \& Kuntadi, K. (2014). Perbandingan hybrid ulat sutera (Bombyx mori L.) asal Cina dengan hybrid lokal dI Sulawesi Selatan. Jurnal Penelitian Hutan Tanaman, 11(3), 173-183. https://doi.org/10. 20886/jpht.2014.11.3.173-183

Andadari, L., Muin, N., Pudjiono, S., Dewi, R., \& Sari, H. (2014). Standar Operasional Prosedur (SOP) budidaya tanaman murbei (Morus spp) dan ulat sutera (Bombyx mori L.) (M. Kaomini (ed.)). Forda Press.

Andadari, L., \& Sunarti, S. (2015). Kualitas kokon hasil persilangan antara ulat sutera (Bombyx mory L.) ras Cina dan ras Jepang. Jurnal Pemuliaan Tanaman Hutan, 9(1), 43-51. https://doi.org/10.20886/jpth.2015.9.1 .43-51

Andadari, L., Ekawati, D., \& Kuntadi. (2016). Kualitas kokon bibit hybrid ulat sutera (Bombyx mori L.) asal Bulgaria dan Indonesia. Prosiding Seminar Nasional PEI, 179-182.

Andadari, L. (2016). Pemilihan jenis hybrid ulat sutera yang optimal untuk dikembangkan di dataran tinggi dan/atau dataran rendah. Jurnal Penelitian Hutan Tanaman, 13(1), 1321.

Arief, A.M. (2019). Industri kain sutra : perajin kesulitan bahan baku Sejak 2000. Bisnis.Com.https://ekonomi. bisnis.com/read/20190321/257/90263

0/industri-kain-sutera-perajin-

kesulitan-bahan-baku-sejak-2000

Atmosoedarjo, S., Kartasubrata, J., Kaomini, M., Saleh, W., \& Meordoko, W. (2000). Sutera alam Indonesia. Yayasan Sarana Wana Jaya.

Badan Standarisasi Nasional. (2010). SNI 7635: 2010 Kokon segar jenis Bombyx mori L.

Balai Persuteraan Alam. (2010). Pedoman Teknik Budidaya Sutra Alam.

Chauchan, T., \& Tayal, M.K. (2017). Mulberry sericulture. In Omkar (Ed.), Industrial Entomology (pp. 1-465). springer nature Singapore Pte. Ltd. https://doi.org/10.1007/978-981-103304-9

Chen, H.J., Ying, S., Jun, L., Lixia, M., Zou, Y.X., \& Liao, S.T. (2014). Changes of 1-deoxynojirimycin with hypoglycemic activity in silkworm (Bombyx mori L.) during different developmental stages. Medicinal Chemistry, 4(9), 630-634. https://doi.org/10.4172/2161-0444. 1000205.

Harbi, J., Nurrochmat, D.R., \& Kusharto, C.M. (2016). Pengembangan usaha persuteraan alam Kabupaten Wajo, Sulawesi Selatan. Risalah Kebijakan Pertanian Dan Lingkungan, 2(2), 129136. https://doi.org/10.20957/jkebija kan.v2i2.10983

Hartati. (2015). Analisis Fenotip Ulat Sutera (Bombyx mori L.). In Analisis fenotip ulat sutera (Bombyx mori L.) (Cetakan I). Global Research and Consulting Institute.

Mirhosseini, S.Z. Nematollahian, S., Ghanipoor, M., \& Seidavi, A. (2010). Comparison of phenotypic and genetic performance of local silkworm groups and two commercial lines. Biological Research, 43(4), 411-416. https://doi.org/10.4067/S0716-97602 010000400005

Noerati, Gunawan, Ichwan, M., \& Sumihartati, A. (2013). Teknologi 
Tekstil. In Bahan Ajar Pendidikan dan Pelatihan Guru (p. 390). Sekolah Tinggi Teknologi Tekstil.

Qin, D.Y., Wang, G.H., Dong, Z.M., Xia, Q.Y., \& Zhao, P. (2020). Comparative fecal metabolomes of silkworms being fed mulberry leaf and artificial diet. Insects, 11(12), 1-15. https://doi.org/ 10.3390/insects 11120851

Sajgotra, M., Verma, G., \& Vikas Gupta. (2018). Comparative effect of feeding frequency on economic traits of bivoltine silkworm, Bombyx mori L. Journal of Entomology and Zoology Studies, 6(3), 1678-1682.

Sudan, K., \& Bukhari, R. (2021). Comparative study of nutritional, climatic and economical factors on growth and development of silkworm (Bombyx mori L.). Uttar Pradesh Journal Of Zoology, 42(4), 44-52. 